\title{
Systematic evaluation of candidate ligands regulating ectodomain shedding of Amyloid Precursor Protein
}

\author{
Heather C. Rice, Tracy L. Young-Pearse, and Dennis J. Selkoe \\ Center for Neurologic Diseases, Brigham and Women's Hospital and Harvard Medical School, \\ Boston, MA USA 02115
}

\begin{abstract}
Despite intense interest in the proteolysis of the B-Amyloid Precursor Protein (APP) in Alzheimer's disease (AD), how the normal processing of this type I receptor-like glycoprotein is physiologically regulated remains ill-defined. In recent years, several candidate protein ligands for APP, including F-spondin, Reelin, $\beta 1$ Integrin, Contactins, Lingo-1 and Pancortin, have been reported. However, a cognate ligand for APP that regulates its processing by $\alpha$ - or $\beta$-secretase has yet to be widely confirmed in multiple laboratories. Here, we developed new assays in an effort to confirm a role for one or more of these candidate ligands in regulating APP ectodomain shedding in a biologically relevant context. A comprehensive quantification of APPsa and APPs $\beta$, the immediate products of secretase processing, in both non-neuronal cell lines and primary neuronal cultures expressing endogenous APP yielded no evidence that any of these published candidate ligands stimulate ectodomain shedding. Rather, Reelin, Lingo-1 and Pancortin-1 emerged as the most consistent ligands for significantly inhibiting ectodomain shedding. These findings led us to conduct further detailed analyses of the interactions of Reelin and Lingo-1 with APP.
\end{abstract}

\section{Keywords}

Regulated intramembrane proteolysis; Amyloid Precursor Protein; ectodomain shedding; Lingo-1/ Reelin; Alzheimer's disease

\begin{abstract}
Although the stepwise proteolysis of the $\beta$-Amyloid Precursor Protein (APP) to release amyloid $\beta$-protein $(A ß)$ has been central to the study of Alzheimer's disease (AD), how the normal processing of this conserved type I membrane glycoprotein is physiologically regulated remains poorly defined. In $\mathrm{AD}$, amyloid (neuritic) plaques are principally composed of the potentially neurotoxic $A \beta$ peptides, which are generated by the sequential proteolytic processing of APP (reviewed in (1)). Cleavage of APP by either a- or $\beta$ secretase results in the shedding of large extracellular portions of APP termed APPsa or APPs $\beta$, respectively. The remaining C-terminal fragments (CTFa and CTF $\beta)$ are then cleaved intramembranously by $\gamma$-secretase. Cleavage of CTF $\beta$ by $\gamma$-secretase releases A $\beta$ into the luminal/extracellular space and AICD into the cytoplasm. Cleavage of CTFa by $\gamma$ secretase releases the smaller $\mathrm{p} 3$ fragment into the lumen/extracellular space and AICD into the cytoplasm. The latter pathway, which begins with APP ectodomain shedding by asecretase, predominates in almost all cell types and precludes $\mathrm{A} \beta$ production.
\end{abstract}

Corresponding author: Dennis J. Selkoe 77 Avenue Louis Pasteur Harvard Institutes of Medicine, Room 730 Boston, MA 02115 Telephone: (617) 525-5200 Fax: (617) 525-5252 dselkoe@ rics.bwh.harvard.edu.

Supporting Information: $\beta 1$ Integrin shows a correlation between holoAPP and APPsa/holoAPP (Fig S1). APPsa/APPs $\beta$ is dramatically higher and more variable with overexpressed relative to endogenous APP (Fig S2). Quantitative Western blot analysis of candidate ligand expression levels (Fig S3). FBS and BSA increase the detection of APPsa (Fig S4). Effect of Reelin CM treatment on COS7 cells overexpressing APP751 (Fig S5). This material is available free of charge via the Internet at http://pubs.acs.org. 
Experimental studies suggest several roles for APP in brain development, including migration of neuronal precursor cells $(2,3)$, neurite outgrowth $(4-7)$, cell adhesion $(8,9)$ and synapse formation $(10,11)$. Since its initial discovery, APP has been hypothesized to be a cell surface receptor (12). In recent years, several candidate protein ligands for APP, including F-spondin $(13,14)$, Reelin $(15,16), \beta 1$ Integrin $(4,16)$, Contactins (17-19), Lingo-1 (19) and Pancortin (20), have been reported to interact physically with the ectodomain of APP and modulate APP processing and, in some cases, APP function in neurodevelopment.

F-spondin, a secreted extracellular matrix glycoprotein, was identified in unbiased screens for APP interactors $(13,19)$. Transfection of F-spondin was initially found to inhibit $\beta$ secretase cleavage of APP as measured by CTFP levels in human embryonic kidney (HEK) 293 cells also over-expressing APP and BACE1 (13). F-spondin inhibited AICD-dependent gene transactivation, suggesting that $a$-secretase cleavage was also inhibited by F-spondin (13). However, a subsequent study reported that F-spondin enhanced APPsa and CTFa in addition to reducing APPs $\beta$ in COS7 cells overexpressing APP (14).

$\beta 1$ Integrin is a type I single transmembrane protein important for cell adhesion. We have found $\beta 1$ Integrin to physically interact with APP and to be involved in APP-dependent neurite outgrowth (4). These findings were confirmed in a study by another group in which they also reported that $\beta 1$ Integrin enhanced APPsa and CTFa levels in COS7 cells overexpressing APP (16).

The Contactins (CNTNs) are GPI-anchored neuronal-specific cell adhesion molecules (reviewed in (21)). CNTN4 was identified in a screen for extracellular APP binding partners in embryonic chick brain, and only CNTN3 and CNTN4 but not the remaining CNTN family members were found to directly bind APP in vitro (17). However, other groups reported evidence of a physical interaction of CNTN2 (18) and CNTN1(19) with APP. Expression of CNTN4 in HEK cells overexpressing APP led to an increase of CTFa levels in some experiments and a decrease in others (17). CNTN2 was reported to enhance AICD, $\mathrm{CTFa}$ and CTF $\beta$ in both overexpressed and endogenous assays (18). Functional interactions between CNTN4 and APP in neurite outgrowth (17) and CNTN2 and APP in neurogenesis (18) have been reported.

Lingo-1 (leucine rich repeat and Ig domain-containing Nogo receptor interacting protein-1), a single-transmembrane protein, is a member of the Nogo-66 receptor complex and negatively regulates axonal myelination and regeneration (reviewed in (22)). Lingo-1 was among the proteins identified (along with F-spondin) in the APP interactome study of intact mouse brain (19). This study reported a physical interaction between APP and Lingo-1 and showed that knockdown of Lingo-1 in HEK293 cells stably overexpressing APP bearing the "Swedish" AD mutation increased CTFa and lowered CTF $\beta$, whereas overexpression of Lingo-1 increased CTF $\beta$ (19). A separate group confirmed a physical interaction in an overexpressed cell system and determined that the interaction occurs via the ectodomain of Lingo-1 (23).

Reelin, a large glycoprotein, is secreted from Cajal-Retzius cells in the embryonic cortex and regulates the migration of neuronal precursor cells (reviewed in (24)). In the adult cortex, Reelin is secreted by a subset of interneurons and plays a role in synaptic plasticity (reviewed in (25)). In two studies, Reelin was shown to physically interact with APP and enhance APPsa and CTFa levels in COS7 cells overexpressing APP $(15,16)$. Subsequently, another group showed that reduction of Reelin enhanced both CTF $\beta$ and A $\beta$ in APP transgenic mice (26). A functional interaction between Reelin and APP in neurite outgrowth has been described (16). 
We recently reported Pancortin, a secreted glycoprotein with multiple isoforms, as a candidate ligand for APP (20). Pancortin was identified in an unbiased screen of endogenous proteins from murine cortical slices that interacted with the APP ectodomain (20). Pancortin- 1 and Pancortin- 2 were found to specifically reduce $\beta$-secretase but not $\alpha$ secretase cleavage of endogenous APP in HEK293 cells, while Pancortin-3 had no effect (20). We also uncovered a functional interaction of Pancortin isoforms with APP in regulating the entry of neuronal precursor cells into the cortical plate (20).

In the context of these numerous reports of candidate ligands with often variable individual results, a cognate ligand for APP that regulates its processing by $\alpha$ - or $\beta$ - secretase has yet to be widely confirmed by multiple laboratories in biologically relevant systems. Here, in an effort to confirm a role for one or more reported candidate ligands in regulating $\alpha$ - or $\beta$ secretase cleavage of APP, we describe a systematic comparison of candidate ligands by directly quantifying APPsa and APPs $\beta$, the immediate products of secretase processing, across multiple assays. First, we compare candidate APP ligands in a non-neuronal mammalian cell line with overexpression of APP, in keeping with virtually all of the above initial reports on these candidate ligands. Then, we compare the candidates in novel assays we have developed to measure proteolytic processing of endogenous APP in both nonneuronal and neuronal cell lines. From these studies, we do not confirm any candidates as triggering ectodomain shedding of APP. However, Reelin, Lingo-1 and Pancortin-1 emerge as the most consistent ligands that reduce $\alpha$-and/or $\beta$ - secretase cleavage of APP. Accordingly, we report further detailed analyses of the interactions of Reelin and Lingo-1 with APP.

\section{Experimental Procedures}

\section{Plasmids}

Plasmids utilized for transient and stable transfections include, pCAX-APP751(human) as described (2), pcDNA-APP695-swedish (human), as described (27), pCAX- $\beta 1$ Integrin (mouse) as described (4), PCAX -Pancortin-1 and -4 (mouse) as described (20). pcDNA4His/Myc-F-spondin(human) was kindly provided by T. Sudoff (13). Lingo-1 (human) was obtained from DF/HCC DNA Resource Core deposited by the Mammalian Gene Collection consortium and cloned into the $\mathrm{pCDH}$ vector. CNTN2-Fc(human) was kindly provided by J. Flanagan (17) and cloned into the pcDNA vector. pcDNA-Reelin (mouse) was kindly provided by T. Curran (28). Constructs for the Reelin fragments (N-R6, R3-8, 3-6, N-R2, and R7-8) (mouse) were provided by A. Goffinet (29). pcDNA-APOER2 were kindly provided by J. Herz. VLDLR-myc (mouse) was kindly provided by H-S Hoe (14). HEK293 cell lines stably expressing Reelin or vector control, CER or CEP4 respectively, were kindly provided by T. Curran (30).

\section{Immunoprecipitation (IP) and Western blotting (WB)}

For IP studies, HEK293 cells were transfected with the specified combinations of Reelin, APOER2, VLDLR, and APP. Cells were lysed in 1\% NP40 STEN buffer $(150 \mathrm{mM} \mathrm{NaCl}, 50$ $\mathrm{mM}$ Tris, $2 \mathrm{mM}$ EDTA, and 1.0\% (v/v) NP-40). Lysates were IPed with either anti-Reelin (G10, Millipore), anti-APOER2 (Abcam, Cambridge, MA) anti-VLDLR (R\&D Systems, Minneapolis, MN), or anti-APP (C9) and protein A and G agarose resin (Sigma, St. Louis, MO) overnight and washed $3 \mathrm{X}$ with $1 \%$ NP40 STEN buffer. Lysates, CM, and immunoprecipitations were electrophoresed on 10-20\% Tricine or 4-12\% Bis-Tris gels (Invitrogen, Carlsbad, CA) and transferred to nitrocellulose. Western blotting (WB) was performed with primary antibodies anti-APP (C9, 1:1,000; Selkoe lab), anti-APPsa (1736, 1:2,000; Selkoe lab), anti-rodent APP/APPsa (597,1:200; Immuno-biological Laboratories, Minneapolis, MN), anti-GAPDH (1:2,000; Millipore, Billerica, MA), anti-FLAG (M2; 
1:1,000; Sigma, St. Louis, MO), anti-Lingo-1(1:1,000; Millipore, Billerica, MA), anti- $\beta 1$ Integrin (1:1,000; Abcam, Cambrdige, MA), anti-F-spondin (1:1,000; Abcam, Cambrdige, MA), anti-Reelin (N-terminal, G10) (1:500, Millipore, Billerica, MA), anti-Reelin (midregion, R4B) (1:1000, Developmental Studies Hybridoma Bank, Iowa City, IA) anti-Reelin (C-terminal) (1:1000, E5, Santa Cruz Biotechnology, Santa Cruz, CA), anti-Tau (1:2,000, Dako, Carpinteria, CA), anti-BACE1 (1:500, Millipore, Billerica, MA), anti-ADAM17 (1:500, Abcam, Cambridge, MA), each followed by IRDye800- or IRDye680-conjugated secondary antibodies (1:10,000; Rockland Immunochemicals, Gilbertsville, PA) and detection with the LICOR Odyssey detection system. For quantitative Western blots, Pancortin-3 (Rice et al., 2012), Reelin and F-spondin (R\&D systems, Minneapolis, MN) recombinant proteins were utilized as standards.

\section{APP processing assays in HEK293 cells}

HEK293 cells were plated in 6 well plates at $1 \times 10 \hat{6}$ cells/well and transiently transfected with cDNA of each candidate ligand or empty vector (as control) using Fugene HD (Promega, Madison, WI). In the assay to examine effects on overexpressed APP, APP751 was co-transfected with the candidate ligand or empty vector. At $24 \mathrm{hr}$ post-transfection, media (DMEM $+10 \%$ FBS) were replaced, and at $48 \mathrm{hr}$ post-transfection, media were collected and centrifuged at $200 \mathrm{~g}$ for $5 \mathrm{~min}$, and cells were lysed in 1\% NP-40 STEN buffer. Human APPsa, APPs $\beta, A \beta 40$, and A $\beta 42$ levels in the CM was quantified by multiplex ELISA kits (Meso Scale Discovery, Gaithersburg, MD) and normalized to holoAPP in the lysate (for the overexpressed APP assay) or normalized to total intracellular protein (for the endogenous APP assay). For DAPT treatment of Lingo-1 transfected HEK293 cells, cells were treated for 24 hrs with $5 \mu \mathrm{M}$ DAPT in DMSO. One-way ANOVA tests were performed with the Bonferroni correction for multiple comparisons.

\section{APP processing assays in rat primary cortical cultures}

Cortical neurons from E1 8 Sprague Dawley rats were plated in 6-well poly-D-lysine coated plates at $7.5 \times 10 \hat{5}$ cells/well typically for 4 DIV (but but some experiments ranged for 2-12 DIV with similar effects). In our co-culture assay, The HEK293 stable cell lines expressing the ligand of interest were pelleted by centrifugation and then resuspended in neuronal medium. The HEK293 cells are then plated at $7.5 \times 10 \hat{5}$ cells/well overlying the neurons for 18-24 hr. Medium is then changed $4 \mathrm{hrs}$ later to remove any unattached HEK293 cells. In our CM assay, neurons were treated for 18-24 hr with CM from the HEK293 cell lines stably expressing the ligand of interest. CM was obtained from stable cell lines conditioned for $24 \mathrm{hr}$ in serum-free optiMEM concentrated 10x with Amicon Ultra 10K MWCO centrifugal filters (Millipore) and diluted to a $1 \times$ solution in Neurobasal media. After the 18-24 hr period of CM treatment or co-culture, CM was collected and centrifuged at 2000 rpm for 5 min. Cells were lysed in 1\% NP-40 STEN. Endogenous rat neuronal APPsa was quantified by a rodent-specific ELISA kit (Immunobiological Laboratories). APPsa was normalized to a neuronal-specific protein, Tau, by WB analysis in the co-culture assay and to total intracellular protein by BCA assay (Fisher) in the CM assay. One-way ANOVA tests were performed with the Bonferroni correction for multiple comparisons.

\section{Results}

\section{Effects of candidate ligands on APPs $\alpha$ and APPs $\beta$ levels in HEK293 cells}

Candidate APP ligands were first examined in a non-neuronal mammalian cell line overexpressing APP, because this had been done in nearly all of the initial reports of these particular candidate ligands (reviewed in Introduction). In this assay, HEK 293 cells were transiently co-transfected with one of the putative ligands and human APP751, and the medium (DMEM with 10\% FBS) was changed $24 \mathrm{hr}$ after transfection. At $48 \mathrm{hr}$, the 
conditioned media (CM) were collected, and cells were lysed. APPsa and APPs $\beta$ levels in the CM were measured by a sensitive and highly reproducible MSD multiplex ELISA. APPsa and APPs $\beta$ levels were normalized to holoAPP, which was measured by WB of the respective cell lysates. Using this assay, F-spondin and CNTN2-Fc did not significantly modulate APPsa or APPs $\beta$ levels (Fig 1A-C). Expression of Reelin resulted in the greatest change of APPsa and APPs $\beta$ levels, with a decrease of $54.9 \pm 3.5 \%(\mathrm{p}<0.001)$ and $25.4 \pm$ $4.2 \%$ ( $\mathrm{p}<0.001$ ), respectively (Fig 1A-C). Expression of Lingo-1 also significantly reduced levels of APPsa by $34.1 \pm 4.2 \%(\mathrm{p}<0.001)$ and APPs $\beta$ by $16.1 \pm 5.3 \%(\mathrm{p}<0.05)$ (Fig $1 \mathrm{~A}-\mathrm{C})$. $\beta 1$ Integrin increased APPs $\beta$ levels by $28.6 \% \pm 7.5$ ( $\mathrm{p}<0.001)$ and did not significantly modulate APPsa levels (Fig 1A-C).

Of note, these mean changes in soluble APP shedding were all determined by ELISAs on numerous individual samples performed over multiple experimental days (Fig. 1B, C). Reelin produced the most robust and consistent effect in this assay (see scatterplots in Fig. $1 \mathrm{~B}-\mathrm{C})$. Across all replicates, Reelin overexpression resulted in a $25 \%$ or greater decrease in APPsa (Fig 1B). Transfection of $\beta 1$ Integrin resulted in the highest variability across experiments, as APPsa and APPs $\beta$ levels were enhanced in some experiments but reduced in others (Figs 1B-C). These variable effects of $\beta 1$ Integrin on APPsa and APPs $\beta$ shedding appeared to be due to differences in holoAPP expression levels. In this overexpression assay system, co-transfection of $\beta 1$ Integrin with APP751 led to much greater percent changes in holoAPP levels than did co-transfection of the other 4 candidates (Fig S1). Even after normalization of the APPsa and APPs $\beta$ levels to holoAPP levels in each experiment, the effects of $\beta 1$ Integrin on APPsa secretion were significantly correlated $\left(R^{2}=.44, p<0.01\right)$ with differences in holoAPP expression (Fig S1). For example, when holoAPP levels were relatively high in the $\beta 1$ Integrin co-transfectants compared to vector transfected controls, then relative APPsa/holoAPP levels were also high. In contrast, we observed no significant correlations between APPsa/holoAPP and changes in holoAPP expression levels for Fspondin, Reelin and Lingo-1 (Fig. S1).

Proteolytic processing of overexpressed APP can be quite different than that of endogenous APP. For example, we observed that the APPsa/APPs $\beta$ ratio in CM was $6.6 \pm 0.7$ in HEK293 cells expressing just endogenous human APP but was a remarkable 78.4 \pm 8.8 in HEK293 cells overexpressing human APP (Fig S2). This striking many-fold difference highlights the non-physiological nature of the procesing of overexpressed APP, and we therefore developed assays to investigate the effects of candidate ligands on proteolytic processing of endogenous APP, something that has not typically been reported for potential APP ligands. These experiments were initially performed in HEK293 cells using the same methods as in the above assay with the exception that no co-transfection of APP occurred. WBs of cellular lysates confirmed that the transfection of the candidate ligands did not alter endogenous holoAPP levels (Fig 2B); therefore, endogenous APPsa and APPs $\beta$ levels in the $\mathrm{CM}$ were normalized to the more quantitative measure of total intracellular protein concentration in the lysate. Using this assay, we found that the expression of each candidate ligand resulted in a small but significant change in APPs level. APPsa and APPs $\beta$ levels were significantly reduced by the expression of F-spondin (APPsa: $11.7 \pm 3.1 \%$; $<<0.001$; APPs $\beta$ : $16.7 \pm 4.3 \%$; $p<0.001$ ), Reelin (APPsa: $18.0 \pm 1.6 \%$; $<<0.001 ;$ APPs $\beta: 20.2 \pm 2.0 \%$; p $<0.001$ ), and Lingo-1 (APPsa: $13.1 \pm 2.7 \%$; $\mathrm{p}<0.001$; APPs $\beta$ : $26.2 \pm 2.8 \%$; $<<0.001$ ) (Fig $1 D-F)$. Expression of $\beta 1$ Integrin significantly increased APPsa by $20.4 \pm 2.9 \%(\mathrm{p}<0.001)$ but did not significantly change APPs $\beta$ levels (Fig 1D). CNTN2 did not significantly affect APPsa or APPs $\beta$ levels. Thus, while Reelin and Lingo- 1 strongly inhibited $\alpha-$ and $\beta$ secretase cleavage of overexpressed APP in HEK293 cells (Fig. 1A), cleavage of endogenous APP was more weakly - but still significantly -- inhibited by Reelin and Lingo-1 (Fig. 1D). As a comparative control in this same assay, we repeated experiments on the proteins Pancortin-1 and Pancortin-3 that we recently described as APP ectodomain 
ligands (20). In agreement with our previous report, Pancortin-1 significantly reduced $\beta$ secretase cleavage $(47.9 \pm 3.6 \% ; \mathrm{p}<0.001)$ without affecting a-secretase cleavage of endogenous APP, whereas the isoform Pancortin- 3 had no significant effects on either $a$ - or $\beta$ - secretase cleavage. The effect of Pancortin-1 on APPs $\beta$ was more robust and less variable than any of the other candidate ligands we tested in this endogenous APP cleavage assay in 293 cells (Fig 1E-F).

Western blots (WB) from representative experiments are shown for the HEK293 cell assays in which APP was either overexpressed (Fig 2A) or endogenous (Fig 2B), demonstrating the expression levels of both holoAPP and the candidate ligands. Expression levels were similar among the various candidate ligands, with an estimate of $5-10 \mu \mathrm{g} / \mathrm{mg}$ of cell lysate or 5-10 $\mathrm{mg} / \mathrm{mL}$ secreted into the CM for those tested by quantitative Western blot (Fig S3). In the initial experiments where APP was overexpressed, CTFs and APPsa could be readily detected by WB, and these paralleled the changes in APPs by ELISA (Fig 2A, see e.g., Reelin and Lingo-1). Levels of ADAM17 (an a-secretase for APP) and BACE-1 ( $\beta$-site APP cleaving enzyme- 1 , or $\beta$-secretase) were not changed by the expression of the candidate ligands (Fig 2B), suggesting that any effects on APP processing we observed were not due to changes in the levels of the secretases that cleave APP.

In both of these HEK293 cell assays (Fig. 1), we utilized DMEM media with 10\% fetal bovine serum (FBS). Previous reports of these and other candidate APP ligands have used a variety of medium conditions, including medium with serum, serum-free (SF) medium, and SF medium supplemented with bovine serum albumin (BSA) as a carrier protein. This technical variability could help explain some of the different results obtained by different labs. We found that medium supplemented with either FBS or BSA enhanced the recovery and subsequent detection of APPsa in the CM by over 3-fold (Fig S4A). Moreover, transfected cells conditioned in media with serum were healthier than those with only BSA. Therefore, we chose to condition our cells in DMEM+10\% FBS for all of the studies reported above, as this allows the best health of the transfected cells and the best recovery of APPsa. Importantly, we showed that the effect of Reelin on endogenous APPsa levels was similar across these three media conditions (Fig S4B).

\section{Effects of candidate APP ligands on APPsa levels in primary cortical neuronal cultures}

The most physiologically relevant culture system for analyzing putative ligands that regulate processing of APP in the central nervous system would assay the effects on endogenous APP in primary neurons with the ligands presented in trans. To this end, we developed both co-culture and conditioned medium (CM) assays in untransfected primary neuronal cultures (Fig. 3A). In both assays, E18 rat primary cortical neurons were utilized as the reporter cell. In our co-culture assay, stable HEK293 cells expressing the ligands of interest were cocultured overlying the neurons for 18-24 hr (Fig. 3A). Alternatively, in our CM assay, neurons were treated with the CM of stably transfected HEK293 cells expressing the ligand of interest (Fig 3A). Endogenous APPsa produced from the neurons (but not from the human HEK293 cells) was detected by a rodent-specific APPsa ELISA. APPsa was normalized to a neuron-specific marker (Tau) in the lysate of our co-culture assay (in order to normalize to only the neuronal reporter cells but not the HEK293 ligand source) or to total intracellular protein in our CM assay. As an important negative control, we observed no significant difference in APPsa levels secreted from neurons cultured alone compared to those co-cultured with control (untransfected) HEK293 cells at the optimized densities of both cell types employed here (Fig 3B, first two bars). In both assays, an expected increase in neuronal APPsa could be detected in the CM upon treatment with PMA (phorbol-12myristate-13-acetate) as a positive control (Fig 3B-C) (31, 32). Further, human APPsa from the HEK293 cells represents a negligible percentage of the total APPsa detected in both the 
co-culture and CM assays, confirming the specificity of our rodent-specific ELISA (Figs 3B-C).

Reelin and Lingo-1 (which showed the most consistent effects in reducing APPsa in the HEK293 cell assays) significantly reduced neuronal APPsa in the co-culture assay (Fig 3DE). Reelin reduced APPsa by $14.3 \pm 2.4 \%$ ( $\mathrm{p}<0.001$ ), and Lingo- 1 reduced APPsa by $14.7 \pm$ $3.6 \%$ ( $\mathrm{p}<0.001$ ). F-spondin, $\beta 1$ Integrin, and CNTN2-Fc did not significantly modulate APPsa levels in the neuronal co-culture assay (Fig 3D). Only those proteins that are secreted could be tested in the CM assay. As in the co-culture assay, treatment of neurons with Fspondin and CNTN2-Fc CM had no effect on APPsa levels (Fig 3E). In contrast to the neuronal co-culture assay and the two HEK293 assays, Reelin CM had no effect on neuronal APPsa levels (Fig 3E). For comparison, we performed experiments with Pancortin-1 and Pancortin-3 in both of these assays. We had previously reported a decrease in endogenous APPs $\beta$ but not APPsa levels by expressing Pancortin-1 in HEK293 cells. Here, we were only able to perform a rodent-specific ELISA for APPsa, since rodent-specific antibodies for APPs $\beta$ are not available, and we confirmed that there was no significant effect of either Pancortin isoform on APPsa secretion in neurons (Fig 3D,E).

Western blots from representative experiments are shown for both the co-culture (Fig 4A) and CM (Fig 4B) assays in rodent cortical neuronal cultures, demonstrating the expression levels of the candidate ligands and endogenous rat APP. Expression of endogenous holoAPP in the neuronal lysates was not affected by the candidate ligands in either assay (Fig 4A,B). Expression of Tau, which we used as a neuronal-specific protein for normalization, was relatively consistent across conditions (Fig 4A).

\section{Addressing discrepancies in the effects of Reelin and Lingo-1 on APP cleavage}

After testing these candidate ligands in assays on both overexpressed and endogenous APP and in both neuronal and non-neuronal cells, Reelin, Lingo-1 and Pancortin-1 emerged as the candidate APP ligands with the most consistent and quantitatively significant effects on the $\alpha$ - and/or $\beta$-secretase cleavages of APP (Table 1). However, the effects of Lingo-1 and Reelin in our assays were not identical to previous reports. We have already characterized in detail the interaction of the Pancortins with APP in a recent publication (20). Here, we attempt to reconcile experimentally the discrepancy between our data and previous reports for Reelin and Lingo-1.

For Lingo-1 in our HEK293 assay with overexpressed APP, the variability in the magnitude of reduction of APPsa and APPs $\beta$ (normalized to holoAPP) across experiments appears to be due to the expression levels of Lingo-1. The degree of reduction in APPsa and APPs $\beta$ was directly and significantly correlated with protein levels of Lingo-1 (APPsa: $\mathrm{R}^{2}=.69, \mathrm{p}<$. 001; APPs $\beta: \mathrm{R}^{2}=.76, \mathrm{p}<.001$ ) (Fig. 5A-B). The reduction of APPs $\beta$ by Lingo- 1 was in contrast to a previous study (19) in which Lingo-1 enhanced P-secretase cleavage of APP. This discrepancy could be due to differences in the processing of wild-type APP, which we studied, and APP with the Swedish AD mutation that Bai et al (19) studied. Therefore, we tested the effects of Lingo-1 in HEK293 cells transfected with APP695 bearing the Swedish mutation (APPswe). Co-transfection of Lingo-1 with APPswe significantly reduced APPsa but, unlike with wild-type APP, had variable effects on APPs $\beta$. Lingo- 1 caused enhanced APPs $\beta$ in some experiments and reduced APPs $\beta$ levels in others and overall had no significant effect on APPs $\beta$ (Fig 5C-D). However, we noticed that co-transfection of the standard $1 \mu \mathrm{g}$ of Lingo-1 cDNA with APPswe cDNA reduced APPswe expression. Therefore, we tested $0.1 \mu \mathrm{g}$ of Lingo-1 cDNA in which APPswe expression was less affected, but Lingo-1 still had variable effects on APPsa and APPs $\beta$, with no overall significant effect on either (Fig 5C, E). In our studies of Lingo-1, we also uncovered evidence of the $\gamma$-secretase-dependent intramembrane cleavage of Lingo-1. Upon 
transfection of Lingo-1 into HEK293 cells, we detected a $\sim 10 \mathrm{kDa}$ fragment of Lingo-1 with a C-terminal Lingo-1 antibody, and the cellular levels of this CTF were enhanced 2fold when the cells were treated with a $\gamma$-secretase inhibitor (DAPT) (Fig 5F-G). These data strongly suggest that Lingo- 1 is processed by $\gamma$-secretase via the regulated intramembranous proteolysis mechanism, something which was not previously known. Overexpression of APP did not alter the production of the Lingo-1 CTF (Fig 5F-G).

Reelin was previously reported to enhance APPsa and CTF and reduce A $\beta$ levels $(15,16)$, whereas we found a reduction of APPsa and APPs $\beta$ levels by Reelin. First, we examined CTF and A $\beta$ levels. Upon co-transfection of APP with Reelin in HEK293 cells, APP CTFs and $A \beta 40$ and $A \beta 42$ could be readily detected. Expression of Reelin not only decreased APPsa and APPs $\beta$ as documented above, but it also substantially reduced levels of the APP CTF, $A \beta 40$, and A $\beta 42$ (Figs. 2 and 6A). Next, we investigated whether the reduction in APPsa and APPs $\beta$ by Reelin expression was dose-dependent, or if differences in expression levels of Reelin might explain the conflicting results. Increasing concentrations of Reelin cDNA were transfected, leading to rising expression of Reelin secreted into the CM (Fig 6B) accompanied by a dose-dependent decrease in both APPsa and APPs $\beta$ (Fig 6C), consistent with our earlier Reelin results (Fig. 1A and B). Finally, the effect of Reelin on APPsa was investigated according to the methods in which Reelin was previously reported to enhance APPsa levels $(15,16)$. Here, Reelin CM was applied to COS7 cells transfected with APP751. In contrast to this prior study, we found no effect of Reelin when utilizing this method (Fig S5).

\section{Biochemical analysis of the interaction of Reelin with APP}

Next, we sought to confirm whether Reelin and APP could physically interact. Reelin and APP were co-transfected into HEK293 cells, and lysates were immunoprecipitated (IP) for either Reelin or APP. Indeed, Reelin co-IPed with APP, and in the reverse direction, APP co-IPed with Reelin (Fig. 6D, right panel). As a negative control, IP with the APP antibody (C9) failed to co-IP Reelin in the absence of APP overexpression. IP with the Reelin antibody (G10) did IP detectable levels of APP in the absence of Reelin overexpression; however, overexpressing Reelin greatly enhanced the co-IP of APP with Reelin above this background endogenous level (Fig 5D). Importantly, we found that the co-IP of Reelin and APP was quantitatively comparable to the co-IP of Reelin with its canonical receptors, APOER2 and VLDLR (33-35) (Fig 5D).

Reelin undergoes proteolytic cleavages in primary neurons at both its C-terminal and Nterminal ends to generate five fragments (Fig 7A) $(29,36,37)$. To determine which physiological fragments of Reelin may be sufficient for the inhibition of a-secretase cleavage of APP, HEK293 cells were co-transfected with APP751 and cDNAs for fulllength Reelin or else each of the 5 known Reelin fragments. Reelin antibodies with epitopes towards the different regions of Reelin (G10, R4B, E5) (Fig 7A) were used to detect all of the Reelin fragments by Western blot (Fig 7B). Each fragment of Reelin significantly reduced a-secretase cleavage of APP compared to control (Fig 7C). However, expression of the fragments containing the N-terminal region of Reelin (N-R6 and N-R2) resulted in the greatest reduction in APPsa, and this lowering was not significantly different than that seen from full-length Reelin (Fig 7C). Conversely, expression of Reelin fragments containing the C-terminal region but lacking the N-terminal region (R3-8 and R7-8) led to relatively higher levels of APPsa, compared to the effect of full-length Reelin (Fig 7C). These differential effects due not appear to be due to differential expression levels. When the levels of each transfected Reelin fragment detected with single antibodies were compared to full-length Reelin, their expression levels were relatively similar to one another, with only R7-8 having higher expression levels but still less effect on APP shedding (Fig 7B). Thus, while each 
physiological proteolytic fragment of Reelin can inhibit a-secretase cleavage of APP to some extent, the $\mathrm{N}$-terminal region of Reelin is the most active.

\section{Discussion}

\section{Novel and systematic approaches to analyze the effects of candidate ligands on APP processing}

Several extracellular and membrane-bound proteins have been proposed as candidate ligands that may modulate proteolytic processing of the ubiquitously expressed APP polypeptide. However, these candidates have not been validated by multiple laboratories and have often been examined solely with overexpressed APP and with one or two assay systems. In an effort to clarify a role for one or more of the reported ligands in regulating the processing of APP, we systematically and rigorously investigated the ability of these candidates to modulate $\alpha$ - and $\beta$-secretase cleavage of APP. In contrast to virtually all prior studies, we used multiplex ELISA-based assays to obtain quantitative measures of both APPsa and APPs $\beta$, as opposed to solely relying on Western blotting. Further, many of the previous studies show data from a single "representative" experiment. We chose to show our data by scatter-plot analysis of all experiments, and we found that for most putative ligands, a single experiment could not adequately represent the complete data set of the range of effects on APP cleavage and would thus be misleading. Instead, we report a comprehensive quantification of data points across all experiments to capture the inherent biological variability of the effects of each ligand, as well as the technical variability for different assay types. Furthermore, the quantification of secreted APPsa/ $\beta$ we used provides a direct measure of the $\alpha-$ and $\beta$-secretase cleavages, as opposed to measuring only CTFa/ $\beta$, the levels of which can be further complicated by the degree of $\gamma$-secretase activity.

Another important aspect to consider when performing assays to accurately measure APPsa/ $\beta$ generation in the CM is the appropriate normalization. Changes in cellular holoAPP levels can change APPsa and APPs $\beta$ levels independent of any effects of a ligand on $\alpha-$ and $\beta$ secretase cleavage per se. Because co-transfection of APP concurrent with the candidate ligands could lead to differences in APP levels due to technical rather than biological reasons, we normalized data in which APP is overexpressed to holoAPP levels in the lysates of the same cultures. However, because normalizing to holoAPP, which as an end-point measurement in lysates may not fully correct for variations in the levels of APPs that accumulate in the media, we also checked for correlations between the holoAPP cellular level and the APPsa/holoAPP ratio (Fig S1). For assays measuring cleavage of endogenous APP, we observed no detectable differences in holoAPP in the lysates by Western blot and therefore normalized to the more quantitative measure of total intracellular protein concentration in the lysate. For the co-cultures of neurons with HEK293 cells, we normalized to a neuron-specific marker (Tau) in the lysate, in order to normalize only to the neuronal reporter cells but not the HEK293 ligand source.

As a result of attention to these various technical factors and controls, a side-by-side comparison of candidate ligands across multiple assays is presented here for the first time. We initially used an assay similar to the original reports for each of these ligands, i.e., with non-neuronal immortalized mammalian cells overexpressing APP, to enable direct comparisons to those previous reports. We found that co-transfection of APP with certain candidate ligands can lead to the most dramatic effects on APPsa/p levels, perhaps due to a wider dynamic range inherent to the overexpression assay or to artifacts from supraphysiological levels of APP or non-biologically relevant changes in APP levels. For example, we found evidence that despite normalization to holoAPP, the effects of $\beta 1$ Integrin in the overexpression assay were due to variations in APP expression levels (Fig S1). Furthermore, we found that APPsa/APPs $\beta$ ratios were more than 10 -fold higher with 
overexpressed APP $(\sim 75)$ than with endogenous APP $(\sim 6)$, suggesting a fundamental alteration in the processing of overexpressed APP (Fig S2). A likely explanation is that $\beta$ secreatse (BACE1) is not highly expressed endogenously in these non-neuronal cells, and overexpressing APP leads to much greater processing in the a-secretase pathway. For these reasons and because the goal is to determine the in vivo neurobiological relevance of these ligands, it is critical to confirm any findings from APP-overexpressing systems in endogenous and, preferably, neuronal systems. In this context, we proceeded to develop novel assays to compare the candidate ligands in non-neuronal and neuronal cell lines relying on endogenous APP. In particular, we believe the co-culture assay using primary rat cortical neurons has advantages over other systems: 1) APP is endogenously expressed by the neuronal reporters; 2) necessary but unknown co-receptors/co-ligands also should be endogenously expressed in the neuronal reporters; 3 ) ligands are continuously produced by the co-cultured HEK cells (rather than requiring artificial pulse administration); 4) ligands that require expression on the plasma membrane for activity will be expressed in their natural state; and 5) effects on APP processing that could be relevant to AD are best studied in neurons.

\section{F-spondin}

While F-spondin was the first reported candidate APP ligand with perhaps the most evidence across laboratories for effects on APP cleavage $(13,14,38)$, we observed little evidence of these effects in our assays. We found no significant changes in APPsa or APPs $\beta$ levels in HEK293 cells co-transfected with APP and F-spondin (Fig 1A) or in primary neurons co-cultured with F-spondin stable cells lines (Fig 3D) or treated with F-spondincontaining CM (Fig 3F). However, we did observe a subtle decrease of endogenous APPsa and APPs $\beta$ in plain HEK293 cells transfected with F-Spondin (Fig 1D). A potential underlying difference between our results and previous results is that in order to maintain a less artificial system, we did not overexpress BACE1 (as in (13)) or APOER2 (as in (14)). Perhaps the most direct contrast between our studies and previous studies was in the treatment of primary neurons with F-Spondin-containing CM. Previously, F-spondin CM was reported to enhance CTFa levels in primary neurons (14), but we failed to observe an effect on APPsa with a similar assay.

\section{Integrin $\beta 1$}

Expression of Integrin $\beta 1$ was previously reported in one study to enhance APPsa and APP CTF (16). Here, we found only minor evidence for a subtle overall enhancement of APPsa and APPs $\beta$ in HEK293 cells. However, this effect was not confirmed in primary neurons. Further, in contrast to the relative consistency of the rest of the candidate ligands, transfection of Integrin $\beta 1$ in HEK293 cells overexpressing APP resulted in very high variability in APPs secretion. The effects ranged from very dramatic increases in APPsa and APPs $\beta$ to only subtle or no changes in APPsa/ $\beta$ levels or even reductions in APPs $\alpha / \beta$ levels in some experiments (Fig 1B-C). We found that this variability in APPsa was significantly correlated with the expression of holoAPP upon co-transfection of APP751 with $\beta 1$ Integrin, even after normalization to holoAPP levels (Fig S1). The changes in holoAPP levels do not appear to represent a biologically relevant effect of $\beta 1$ Integrin on APP expression, as $\beta 1$ Integrin did not change expression of endogenous APP. Thus, changes in APPsa upon cotransfection of $\beta 1$ Integrin with APP appear to be an artifact due to differences in APP cotransfection efficiency.

\section{Contactin-2}

CNTN2 has been reported to modulate APP processing by increasing AICD, CTFa and CTF $\beta$ levels in both over expressed and endogenous assays (18). However, our data did not 
confirm these findings. We found no effects of a soluble (Fc-tagged) form of CNTN2 on APPsa or APPs $\beta$ both in our endogenous and overexpressed assays.

\section{Lingo-1}

Knockdown of Lingo-1 has been reported to enhance CTFa and reduce CTF $\beta$ levels, while overexpression of Lingo-1 was reported to enhance CTF $\beta$ levels in HEK293 cells overexpressing the APPswe mutation (19). As predicted from Bai et al. (19), we found that Lingo-1 reduced APPsa levels in each of our assays (Figs $1 \& 3$ ), including primary neuronal cultures (Fig 3). However, instead of an enhancement in $\beta$-secretase cleavage of APP by Lingo-1 (19), we found that Lingo-1 reduced $\beta$-secretase cleavage. The discrepancy between these effects on $\beta$-secretase cleavage of APP may be due to differences in the processing of wild-type APP and APPswe. The Swedish mutation of APP markedly enhances $\beta$-secretase cleavage of APP (27) and modifies the principal subcellular loci for $\beta$ secretase cleavage (39). $\beta$-secretase cleavage of wild-type APP occurs in large part upon internalization and endosomal recycling of cell-surface APP, whereas the Swedish mutation causes APP to be cleaved in considerable part by $\beta$-secretase within the secretory pathway (39). In contrast to our results with wild-type APP, we found that Lingo-1 produced quite variable effects on $\beta$-secretase cleavage of APPswe (Fig 5E). Lingo-1 enhanced APPs $\beta$-swe in some experiments (similar to (19)) but reduced APPs $\beta$-swe in other experiments (similar to our data with wild-type APP, Fig 1C). Thus, the separate mechanisms of $\beta$-secretase cleavage of the two APP variants could explain the apparent differences in Lingo-1 effects on $\beta$-secretase cleavage of APP in these studies.

\section{Reelin}

The effects of Reelin on APP shedding was confirmed across our multiple assays, including with endogenous APP in neurons. However, in contrast to previous studies in which Reelin increased a-secretase cleavage of APP $(15,16)$, we observed that Reelin decreased asecretase cleavage of APP (Figs. $1 \& 3$ ). We also found that Reelin reduced $\beta$-secretase cleavage of APP (Fig 1), which corroborates a previous study in which a reduction of Reelin enhanced A $\beta$ and CTF $\beta$ levels in APP transgenic mouse brain (26). We solidified this evidence by showing that the effect of Reelin on APPsa is dose-dependent and that Reelin also decreases CTF, $A \beta 40$, and $A \beta 42$. Moreover, we confirmed reports of a physical interaction between Reelin and APP and showed a similar level of Reelin-APP co-IP as is seen with its canonical receptors, ApoER2 and VLDLR.

In an attempt to reconcile the opposing effects of Reelin on APPsa, we replicated as closely as we could the methods described previously that resulted in an increase in APPsa $(15,16)$. However, using this method we found no significant effect of Reelin on APPsa levels (Fig S5). These conflicting effects on APPsa do not appear to be due to differences in the concentrations of Reelin, as a range of Reelin concentrations resulted in a decrease of APPsa in our hands (Fig 6C). Because Reelin is cleaved to generate several fragments, it is possible that different cell types secrete alternate Reelin products. However, we found that expression of cDNAs encoding each physiological Reelin fragment reduced APPsa to some extent in our assay (Fig 7).

\section{Pancortins}

Pancortin-1 produced the most robust and consistent effects on cleavage of endogenous APP of any of the candidate ligands tested (Fig 1D-F). Pancortin-1 also was the only candidate ligand which specifically reduced $\beta$-secretase processing while having no effects on $\alpha$ secretase processing of APP. With Pancortins being expressed not only in embryonic but also adult cortex $(40,41)$, regulation of $\beta$-secretase cleavage by Pancortin- 1 could turn out to have important implications for the pathogenesis or treatment of Alzheimer's disease. 
Recently, Pancortin was shown to interact with members of the Lingo-1 signaling pathway and regulate axonal growth (42). As Pancortin and Lingo-1 were top APP ligands in our assays, future studies to determine how the Pancortin and Lingo-1 signaling pathways may intersect to regulate APP processing will be important.

\section{A classic ligand for APP?}

Since its cloning 25 years ago, APP has been intensively studied as regards its processing via regulated intramembrane proteolysis and the role of its $A \beta$ fragment in $A D$ pathogenesis, but studies of its physiological function and processing have received less attention and led to an array of complex, sometimes conflicting findings. For example, analogous to the sizeable number of proteins purported to be candidate ligands for APP, a number of genes had been reported to be transcriptionally activated by the APP intracellular domain (AICD) (43-46). Like the candidate APP ligands, potential target genes had usually been reported by single labs, and attempts to confirm them had been largely unsuccessful $(47,48)$. One particularly clarifying study in this field published by De Strooper and colleagues systematically compared these target genes in the same assay system and found that each was at best indirectly and weakly influenced by APP processing or not at all (47). A central goal of our study was to provide similar clarity for most of the reported candidate ligands of APP.

Our study raises the central question of whether a classic ligand for APP that positively triggers processing by a- or $\beta$ - secretase exists. While we did find effects of Reelin, Lingo-1 and Pancortin-1 on APP processing to be consistent across the multiple assays we used, the effects of Reelin and Lingo-1 were subtle in endogenous systems and not identical to previous reports $(15,16,19)$. Further, each ligand we tested turned out to inhibit cleavage rather than stimulate $\alpha$ - or $\beta$-secretase processing. Whereas a larger portion of APP processing appears to be constitutive than regulated, in contrast to the ligand-regulated cleavage of Notch $(49,50)$, the ability of PMA to robustly stimulate a-secretase cleavage of APP (Fig 2 B-C and $(31,32,51)$ ) suggests that there is a cellular capacity for a-secretease cleavage of APP to be enhanced. On the other hand, it is possible that cognate ligand(s) for APP regulate neuronal functions of APP without significantly modulating its proteolytic processing. It is also possible that instead of a single protein ligand, several proteins and non-protein factors may have coordinated effects to regulate APP cleavage. Thus, each ectodomain-binding ligand may individually result in only subtle effects, particularly in the more biologically relevant context of endogenous, wild-type APP in neurons that we explored. Furthermore, it may be that apparent ligand effects are more indirect, perhaps through common intracellular adaptor proteins or signaling molecules or even through competition of common binding partners $(14,15,52)$. The cellular context of APP may affect ligand binding and cleavage of APP, for example homo- or hetero- dimerization of APP (53) or the subcellullar localization and trafficking of APP (54, 55). Finally, the reported ability of the APP ectodomain to bind certain glycosaminoglycans and proteoglycans (56-58) may contribute to a multifactorial ligand regulation of APP secretory processing, and this should now be explored in the context of the ligands that most consistently affect the shedding of APP, such as Reelin, Pancortin-1 and Lingo-1. Such further research is needed to better define the basic functions of this conserved and ubiquitously expressed protein and to better understand the consequences of chronically altering its proteolytic processing in older humans with AD-type cognitive syndromes.

\section{Supplementary Material}

Refer to Web version on PubMed Central for supplementary material. 


\section{Acknowledgments}

We thank T. Shin for technical assistance. We thank T. Sudoff, T. Curran, J. Flanagan, J. Herz, H.-S. Hoe and A. Goffinet for providing DNA constructs. The 54B Reelin antibody developed by A. Goffinet was obtained from the Developmental Studies Hybridoma Bank developed under the auspices of the NICHD and maintained by the University of Iowa Department of Biology, Iowa City, IA. We thank M. LaVoie for critical reading of the manuscript and members of the Selkoe and Young-Pearse laboratories for helpful discussions.

Funding source statement: This work was supported by National Institutes of Health grants R01 AG06173 (D.J.S.) and R00 MH085004 (T.L.Y-P.) and a Jerome L. Rappaport Fellowship (H.C.R.).

\section{References}

1. Haass C, Kaether C, Thinakaran G, Sisodia S. Trafficking and Proteolytic Processing of APP. Cold Spring Harbor Perspectives in Medicine. 2012; 2

2. Young-Pearse TL, Bai J, Chang R, Zheng JB, Loturco JJ, Selkoe DJ. A Critical Function for betaAmyloid Precursor Protein in Neuronal Migration Revealed by In Utero RNA Interference. J Neurosci. 2007; 27:14459-14469. [PubMed: 18160654]

3. Pramatarova A, Chen K, Howell BW. A genetic interaction between the APP and Dab1 genes influences brain development. Mol Cell Neurosci. 2008; 37:178-186. [PubMed: 18029196]

4. Young-Pearse TL, Chen A, Chang R, Marquez C, Selkoe DJ. Secreted APP regulates the function of full-length APP in neurite outgrowth through interaction with integrin beta1. Neural Development. 2008; 3

5. Rama N, Goldschneider D, Corset V, Lambert J, Pays L, Mehlen P. Amyloid Precursor Protein Regulates Netrin-1-mediated Commissural Axon Outgrowth. J Biol Chem. 2012; 287:3001430023. [PubMed: 22782894]

6. Perez RG, Zheng H, Van der Ploeg LH, Koo EH. The beta-amyloid precursor protein of Alzheimer's disease enhances neuron viability and modulates neuronal polarity. J Neurosci. 1997; 17:94079414. [PubMed: 9390996]

7. Araki W, Kitaguchi N, Tokushima Y, Ishii K, Aratake H, Shimohama S, Nakamura S, Kimura J. Trophic effect of b-amyloid precursor ptotein on cerebral cortical neurons in culture. Biochem Biophys Res Commun. 1991; 181:265-271. [PubMed: 1958195]

8. Ghiso J, Rostagno A, Gardella JE, Liem L, Gorevic PD, Frangione B. A 109-amino-acid C-terminal fragment of Alzheimer's-disease amyloid precursor protein contains a sequence, -RHDS-, that promotes cell adhesion. Biochem J. 1992; 288:1053-1059. [PubMed: 1281980]

9. Soba P, Eggert S, Wagner K, Zentgraf H, Siehl K, Kreger S, Lower A, Langer A, Merdes G, Paro R, Masters CL, Muller U, Kins S, Beyreuther K. Homo- and heterodimerization of APP family members promotes intercellular adhesion. EMBO J. 2005; 24:3624-3634. [PubMed: 16193067]

10. Priller C, Bauer T, Mitteregger G, Krebs B, Kretzschmar HA, Herms J. Synapse formation and function is modulated by the amyloid precursor protein. J Neurosci. 2006; 26:7212-7221. [PubMed: 16822978]

11. Wang Z, Wang B, Yang L, Guo Q, Aithmitti N, Songyang Z, Zheng H. Presynaptic and postsynaptic interaction of the amyloid precursor protein promotes peripheral and central synaptogenesis. J Neurosci. 2009; 29:10788-10801. [PubMed: 19726636]

12. Kang J, Lemaire HG, Unterbeck A, Salbaum JM, Masters CL, Grzeschik KH, Multhaup G, Beyreuther K, Muller-Hill B. The precursor of Alzheimer's disease amyloid A4 protein resembles a cell-surface receptor. Nature. 1987; 325:733-736. [PubMed: 2881207]

13. Ho A, Sudhof TC. Binding of F-spondin to amyloid-beta precursor protein: a candidate amyloidbeta precursor protein ligand that modulates amyloid-beta precursor protein cleavage. Proc Natl Acad Sci. 2004; 101:2548-2553. [PubMed: 14983046]

14. Hoe HS, Wessner D, Beffert U, Becker AG, Matsuoka Y, Rebeck GW. F-spondin interaction with the apolipoprotein E receptor ApoEr2 affects processing of amyloid precursor protein. Mol Cell Biol. 2005; 25:9259-9268. [PubMed: 16227578]

15. Hoe HS, Tran TS, Matsuoka Y, Howell BW, Rebeck GW. DAB1 and Reelin effects on amyloid precursor protein and ApoE receptor 2 trafficking and processing. J Biol Chem. 2006; 281:3517635185. [PubMed: 16951405] 
16. Hoe HS, Lee K, Carney R, Lee J, Markova A, Lee JY, Howell B, Hyman B, Pak D, Bu G, Rebeck $\mathrm{G}$. Interaction of reelin with amyloid precursor protein promotes neurite outgrowth. J Neurosci. 2009; 29:7459-7532. [PubMed: 19515914]

17. Osterfield M, Egelund R, Young LM, Flanagan JG. Interaction of amyloid precursor protein with contactins and NgCAM in the retinotectal system. Development. 2008; 135:1189-1199. [PubMed: 18272596]

18. Ma QH, Futagawa T, Yang WL, Jiang XD, Zeng L, Takeda Y, Xu RX, Bagnard D, Schachner M, Furley AJ, Karagogeos D, Watanabe K, Dawe GS, Xiao ZC. A TAG1-APP signalling pathway through Fe65 negatively modulates neurogenesis. Nat Cell Biol. 2008; 10:283-294. [PubMed: $18278038]$

19. Bai Y, Markham K, Chen F, Weerasekera R, Watts J, Horne P, Wakutani Y, Bagshaw R, Mathews PM, Fraser PE, Westaway D, St George-Hyslop P, Schmitt-Ulms G. The in vivo brain interactome of the amyloid precursor protein. Mol Cell Proteomics. 2008; 7:15-34. [PubMed: 17934213]

20. Rice H, Townsend M, Bai J, Suth S, Cavanaugh W, Selkoe D, Young-Pearse T. Pancortins interact with amyloid precursor protein and modulate cortical cell migration. Development. 2012; 139:3986-3996. [PubMed: 22992957]

21. Shimoda Y. Contactins: Emerging key roles in the development and function of the nervous system. Cell Adh Migr. 2009; 3:64-70. [PubMed: 19262165]

22. Mi S, Sandrock A, Miller R. LINGO-1 and its role in CNS repair. Int J Biochem Cell Biol. 2008; 40:1971-1978. [PubMed: 18468478]

23. Stein T, Walmsley A. The leucine-rich repeats of LINGO-1 are not required for self-interaction or interaction with the amyloid precursor protein. Neuroscience Letters. 2012; 509:9-12. [PubMed: 22133804]

24. Honda T, Kobayashi K, Mikoshiba K, Nakajima K. Regulation of cortical neuron migration by the Reelin signaling pathway. Neurochem Res. 2011; 36:1270-1279. [PubMed: 21253854]

25. Förster E, Bock H, Herz J, Chai X, Frotscher M, Zhao S. Emerging topics in Reelin function. Eur J Neurosci. 2010; 31:1511-1519. [PubMed: 20525064]

26. Kocherhans S, Madhusudan A, Doehner J, Breu K, Nitsch R, Fritschy JM, Knuesel I. Reduced Reelin expression accelerates amyloid-beta plaque formation and tau pathology in transgenic Alzheimer's disease mice. J Neurosci. 2010; 30:9228-9268. [PubMed: 20610758]

27. Citron M, Oltersdorf T, Haass C, McConlogue L, Hung AY, Seubert P, Vigo-Pelfrey C, Lieberburg I, Selkoe DJ. Mutation of the b-amyloid precursor protein in familial Alzheimer's disease increases b-protein production. Nature. 1992; 360:672-674. [PubMed: 1465129]

28. D'Arcangelo G, Nakajima K, Miyata T, Ogawa M, Mikoshiba K, Curran T. Reelin is a secreted glycoprotein recognized by the CR-50 monoclonal antibody. J Neurosci. 1997; 17:23-31. [PubMed: 8987733]

29. Jossin Y, Ignatova N, Hiesberger T, Herz J, Lambert de Rouvroit C, Goffinet A. The central fragment of Reelin, generated by proteolytic processing in vivo, is critical to its function during cortical plate development. J Neurosci. 2004; 24:514-521. [PubMed: 14724251]

30. Benhayon D, Magdaleno S, Curran T. Binding of purified Reelin to ApoER2 and VLDLR mediates tyrosine phosphorylation of Disabled-1. Brain Res Mol Brain Res. 2003; 112:33-45. [PubMed: 12670700]

31. Lammich S, Kojro E, Postina R, Gilbert S, Pfeiffer R, Jasionowski M, Haass C, Fahrenholz F. Constitutive and regulated alpha-secretase cleavage of Alzheimer's amyloid precursor protein by a disintegrin metalloprotease. PNAS. 1999; 96:3922-3927. [PubMed: 10097139]

32. Buxbaum J, Liu K, Luo Y, Slack J, Stocking K, Peschon J, Johnson R, Castner B, Cerretti D, Black R. Evidence that tumor necrosis factor alpha converting enzyme is involved in regulated alpha-secretase cleavage of the Alzheimer amyloid protein precursor. J Biol Chem. 1998; 273:27765-27767. [PubMed: 9774383]

33. Hiesberger T, Trommsdorff M, Howell B, Goffinet A, Mumby M, Cooper J, Herz J. Direct binding of Reelin to VLDL receptor and ApoE receptor 2 induces tyrosine phosphorylation of disabled-1 and modulates tau phosphorylation. Neuron. 1999; 24:481-489. [PubMed: 10571241] 
34. Trommsdorff M, Gotthardt M, Hiesberger T, Shelton J, Stockinger W, Nimpf J, Hammer R, Richardson J, Herz J. Reeler/Disabled-like disruption of neuronal migration in knockout mice lacking the VLDL receptor and ApoE receptor 2. Cell. 1999; 97:689-701. [PubMed: 10380922]

35. D'Arcangelo G, Homayouni R, Keshvara L, Rice DS, Sheldon M, Curran T. Reelin is a ligand for lipoprotein receptors. Neuron. 1999; 24:471-479. [PubMed: 10571240]

36. Jossin Y, Gui L, Goffinet A. Processing of Reelin by embryonic neurons is important for function in tissue but not in dissociated cultured neurons. J Neurosci. 2007; 27:4243-4295. [PubMed: 17442808]

37. Lambert de Rouvroit C, de Bergeyck V, Cortvrindt C, Bar I, Eeckhout Y, Goffinet A. Reelin, the extracellular matrix protein deficient in reeler mutant mice, is processed by a metalloproteinase. Exp Neurol. 1999; 156:214-217. [PubMed: 10192793]

38. Hafez D, Huang J, Richardson J, Masliah E, Peterson D, Marr R. F-spondin gene transfer improves memory performance and reduces amyloid- $\beta$ levels in mice. Neuroscience. 2012; 223:465-472. [PubMed: 22863679]

39. Haass C, Lemere CA, Capell A, Citron M, Seubert P, Schenk D, Lannfelt L, Selkoe DJ. The Swedish mutation causes early-onset Alzheimer's disease by b-secretase cleavage within the secretory pathway. Nature Med. 1995; 1:1291-1296. [PubMed: 7489411]

40. Nagano T, Nakamura A, Konno D, Kurata M, Yagi H, Sato M. A2-Pancortins (Pancortin-3 and Pancortin-4) are the dominant Pancortins during neocortical development. J Neurochem. 2000:75.

41. Danielson PE, Forss-Petter S, Battenberg EL, deLecea L, Bloom FE, Sutcliffe JG. Four structurally distinct neuron-specific olfactomedin-related glycoproteins produced by differential promoter utilization and alternative mRNA splicing from a single gene. J Neurosci Res. 1994; 38:468-478. [PubMed: 7932877]

42. Nakaya N, Sultana A, Lee HS, Tomarev S. Olfactomedin 1 interacts with the nogo a receptor complex to regulate axon growth. J Biol Chem. 2012; 287:37171-37184. [PubMed: 22923615]

43. Baek SH, Ohgi KA, Rose DW, Koo EH, Glass CK, Rosenfeld MG. Exchange of N-CoR corepressor and Tip60 coactivator complexes links gene expression by NF-kappaB and betaamyloid precursor protein. Cell. 2002; 110:55-67. [PubMed: 12150997]

44. Kim HS, Kim EM, Lee JP, Park CH, Kim S, Seo JH, Chang KA, Yu E, Jeong SJ, Chong YH, Suh YH. C-terminal fragments of amyloid precursor protein exert neurotoxicity by inducing glycogen synthase kinase-3beta expression. Faseb J. 2003; 17:1951-1953. [PubMed: 12923068]

45. von Rotz RC, Kohli BM, Bosset J, Meier M, Suzuki T, Nitsch RM, Konietzko U. The APP intracellular domain forms nuclear multiprotein complexes and regulates the transcription of its own precursor. J Cell Sci. 2004; 117:4435-4448. [PubMed: 15331662]

46. Pardossi-Piquard R, Petit A, Kawarai T, Sunyach C, Alves da Costa C, Vincent B, Ring S, D'Adamio L, Shen J, Muller U, St George Hyslop P, Checler F. Presenilin-dependent transcriptional control of the Abeta-degrading enzyme neprilysin by intracellular domains of betaAPP and APLP. Neuron. 2005; 46:541-554. [PubMed: 15944124]

47. Hebert SS, Serneels L, Tolia A, Craessaerts K, Derks C, Filippov MA, Muller U, De Strooper B. Regulated intramembrane proteolysis of amyloid precursor protein and regulation of expression of putative target genes. EMBO Rep. 2006; 7:739-745. [PubMed: 16729020]

48. Hass M, Yankner B. A \{gamma\}-secretase-independent mechanism of signal transduction by the amyloid precursor protein. J Biol Chem. 2005; 280:36895-37799. [PubMed: 16103124]

49. Mumm J, Schroeter E, Saxena M, Griesemer A, Tian X, Pan D, Ray W, Kopan R. A ligandinduced extracellular cleavage regulates gamma-secretase-like proteolytic activation of Notch1. Molecular Cell. 2000; 5:197-206. [PubMed: 10882062]

50. Schroeter E, Kisslinger J, Kopan R. Notch-1 signalling requires ligand-induced proteolytic release of intracellular domain. Nature. 1998; 393:382-386. [PubMed: 9620803]

51. Hung AY, Haass C, Nitsch RM, Qiu WQ, Citron M, Wurtman RJ, Growdon JH, Selkoe DJ. Activation of protein kinase $\mathrm{C}$ inhibits cellular production of the amyloid b-protein. J Biol Chem. 1993; 268:22959-22962. [PubMed: 8226807]

52. Hoe HS, Rebeck G. Functional interactions of APP with the apoE receptor family. J Neurochem. 2008; 106:2263-2271. [PubMed: 18554321] 
53. Libeu C, Descamps O, Zhang Q, John V, Bredesen D. Altering APP proteolysis: increasing sAPPalpha production by targeting dimerization of the APP ectodomain. PloS one. 2012; 7

54. Ehehalt R, Keller P, Haass C, Thiele C, Simons K. Amyloidogenic processing of the Alzheimer beta-amyloid precursor protein depends on lipid rafts. J Cell Biol. 2003; 160:113-123. [PubMed: 12515826]

55. Haass C, Koo EH, Capell A, Teplow DB, Selkoe DJ. Polarized sorting of b-amyloid precursor protein and its proteolytic products in MDCK cells is regulated by two independent signals. J Cell Biol. 1995a; 128:537-547. [PubMed: 7860629]

56. Narindrasorasak S, Lowery D, Gonzalez-DeWhitt P, Poorman R, Greenberg B, Kisilevsky R. High affinity interactions between the Alzheimer's beta-amyloid precursor proteins and the basement membrane form of heparan sulfate proteoglycan. J Biol Chem. 1991; 266:12878-12961. [PubMed: 1906461]

57. Clarris HJ, Cappai R, Heffernan D, Beyreuther K, Masters CL, Small DH. Identification of heparin-binding domains in the amyloid precursor protein of Alzheimer's disease by deletion mutagenesis and peptide mapping. J Neurochem. 1997; 68:1164-1172. [PubMed: 9048763]

58. Mok S, Sberna G, Heffernan D, Cappai R, Galatis D, Clarris H, Sawyer W, Beyreuther K, Masters C, Small D. Expression and analysis of heparin-binding regions of the amyloid precursor protein of Alzheimer's disease. FEBS Lett. 1997; 415:303-310. [PubMed: 9357988]

\section{Abbreviations}

APP

AD

$\mathrm{A} \boldsymbol{B}$

CTF

HEK

BACE

AICD

CNTN

Lingo-1

Pan-1/Pan-3

CM

WB

ELISA

ADAM

SF

FBS

BSA

swe

PMA

IP
ß-Amyloid Precursor Protein

Alzheimer's disease

amyloid ß-protein

C-terminal fragment

human embryonic kidney

$\beta$-site APP cleaving enzyme-1

APP intracellular domain

Contactin

leucine rich repeat and Ig domain containing Nogo receptor interacting protein-1

Pancortin-1/3

conditioned medium

Western blot

enzyme-linked immunosorbent assay

a disintegrin and metalloproteinase family

serum-free

fetal bovine serum

bovine serum albumin

Swedish

phorbol-12-myristate-13-acetate

immunoprecipitation 
Overexpressed APP

A

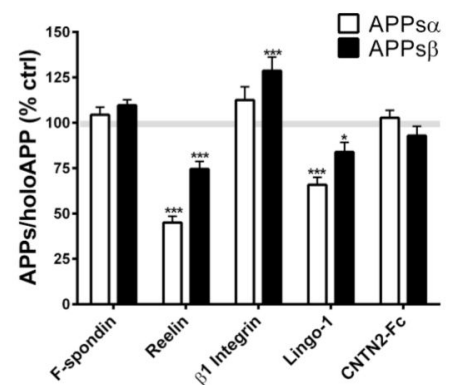

B

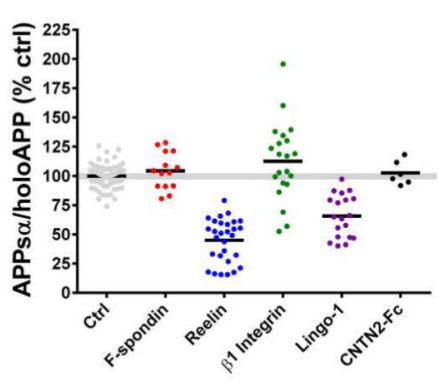

C

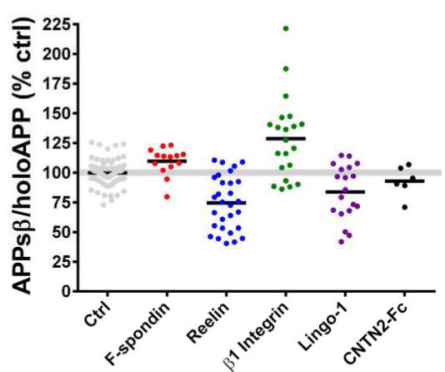

$\mathrm{D}$ Endogenous APP

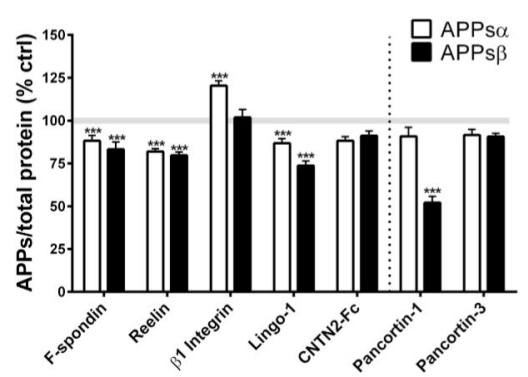

$E$

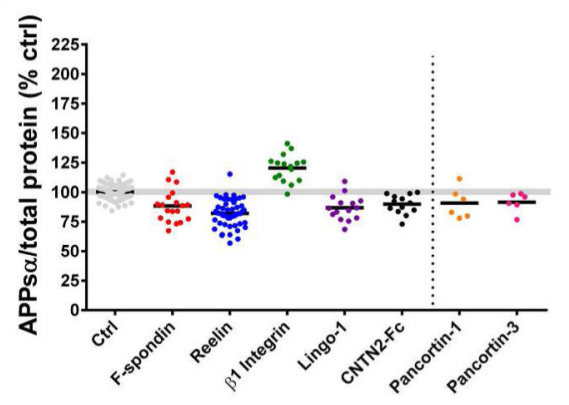

$\mathrm{F}$

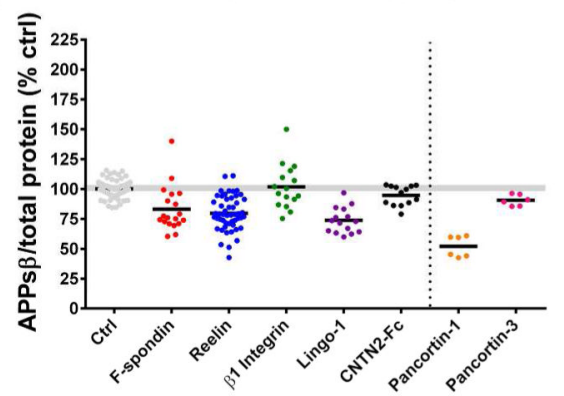

Figure 1. Effects of candidate ligands on APPsa and APPs $\beta$ levels in HEK293 cells

(A-C) HEK293 cells were co-transfected with APP751 (human, wild-type) and candidate ligands or empty vector (as control). APPsa and APPs $\beta$ levels were quantified by ELISA and normalized to holoAPP by Western blot and shown as a percentage of control. (D-F) HEK293 cells (expressing only endogenous human APP) were transfected with candidate ligands or empty vector (as control) and APPsa and APPs $\beta$ levels were quantified by ELISA and normalized to total intracellular protein and shown as a percentage of control. (A,D) Bar graph showing average APPsa and APPs $\beta$ levels of all experiments. Scatter plots showing APPsa $(\mathbf{B}, \mathbf{E})$ and APPs $\beta(\mathbf{C , F})$ levels for each replicate of each experiment. Error bars represent s.e.m.; $* \mathrm{p}<.05, * * * \mathrm{p}<.001$ 
A

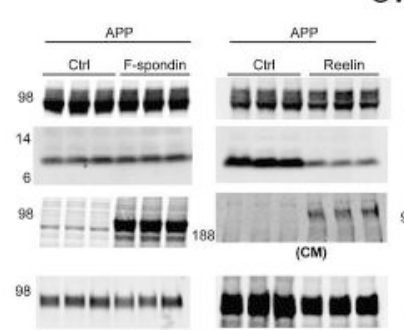

Overexpressed APP

B

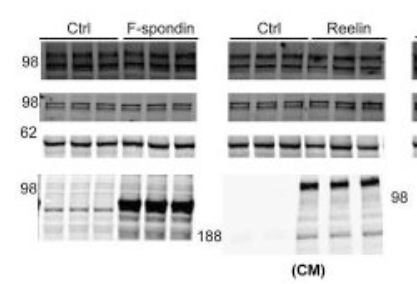

Endogenous APP
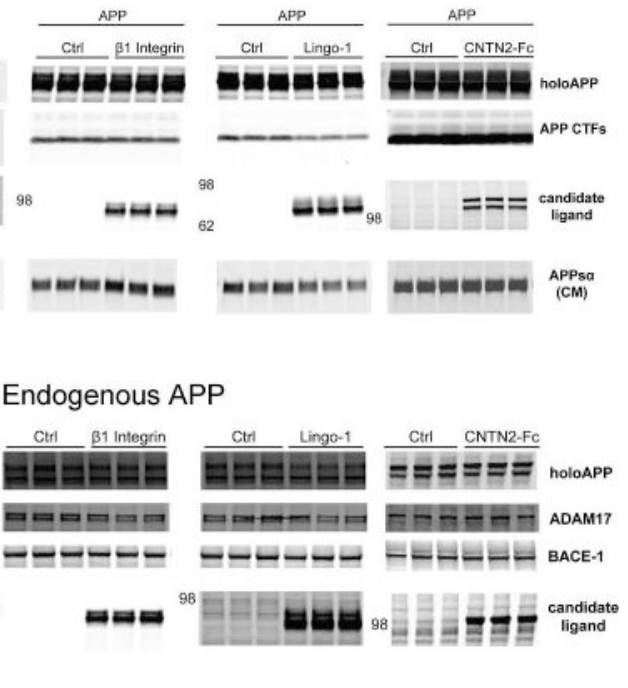

Figure 2. Representative Western blots of APP shedding assays with HEK293 cells

(A) Western blot of lysates (and CM where noted) showing expression levels of holoAPP, APP CTF, candidate ligands, and APPsa in a representative experiment with co-transfection of candidate ligands and APP751 into HEK293 cells. (B) Western blot of lysates (and CM where noted) showing expression levels of holoAPP, secretases, and candidate ligands from a representative experiment with transfection of candidate ligands into HEK293 cells with endogenous APP. 
A
D

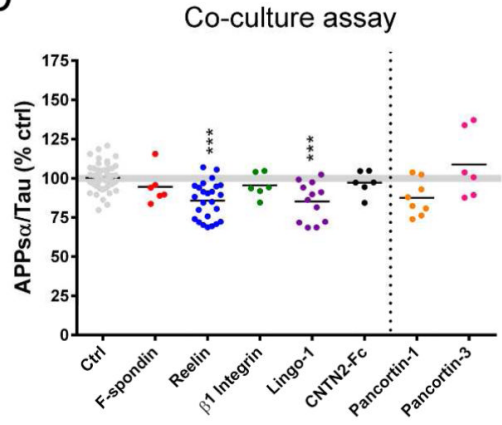

B Co-culture assay

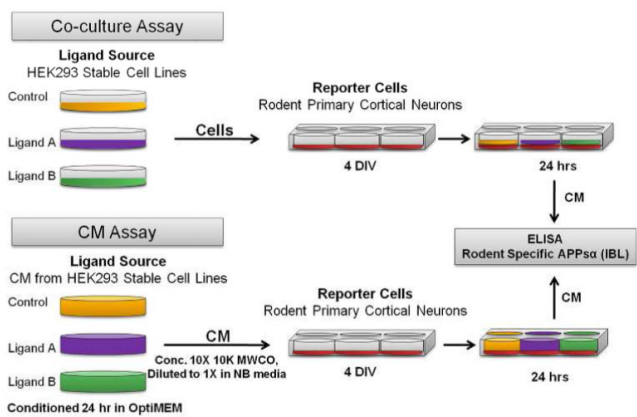

E

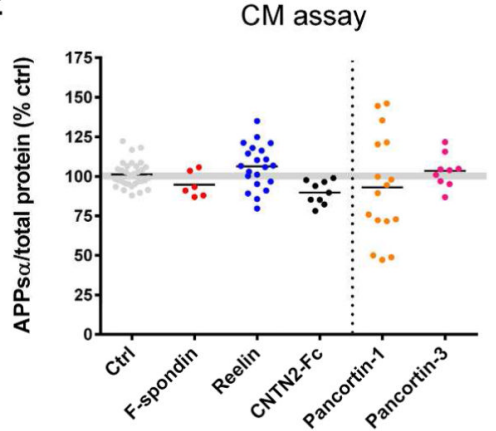

Figure 3. Effects of candidate ligands on APPsa levels in primary cortical cultures (A) Schematic of methods used for co-culture and CM assays. (B-C) Positive controls (PMA treatment) and negative controls (neurons and HEK293 cells alone) for the co-culture (B) and CM (C) assays. (D) ELISA quantification of APPsa (endogenous, rodent) secreted from cortical neurons co-cultured with HEK293 cells stably expressing ligand of interest. (E) ELISA quantification of APPsa (endogenous, rodent) secreted from cortical neurons treated with CM from HEK293 cells expressing ligand of interest. Error bars represent s.e.m.; $* \mathrm{p}<.05$ 
A

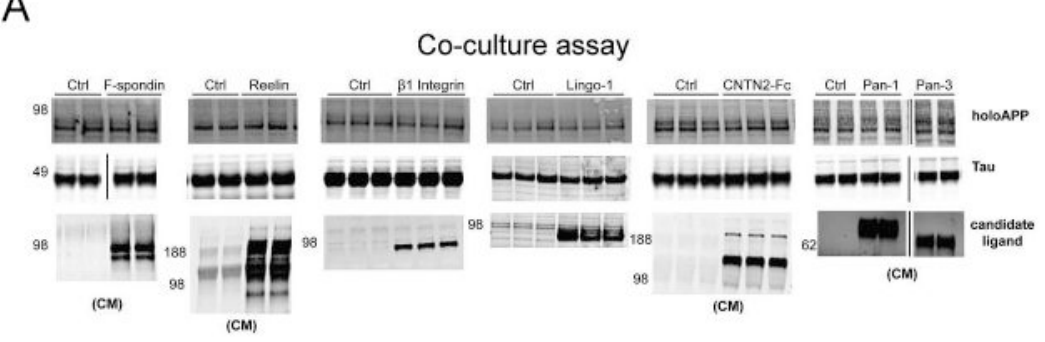

B

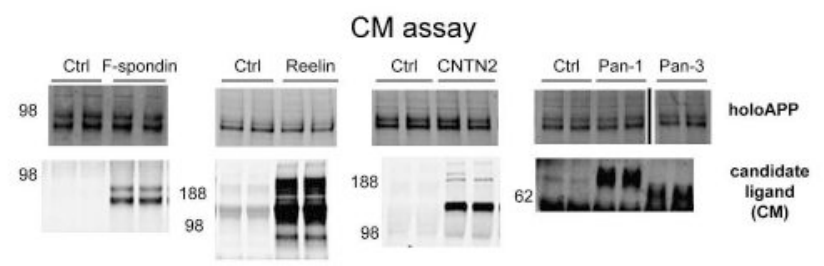

Figure 4. Representative Western blots of APP shedding assays with rat primary cortical cultures

(A) Western blot of lysates (and CM where noted) showing expression levels of holoAPP, Tau, and candidate ligands in a representative experiment with co-culture of neurons with HEK293 cells expressing putative ligands. (B) Western blot of lysates (and CM where noted) showing expression levels of holoAPP and candidate ligands from a representative experiment with neurons treated with CM from HEK293 cells expressing putative ligands. 


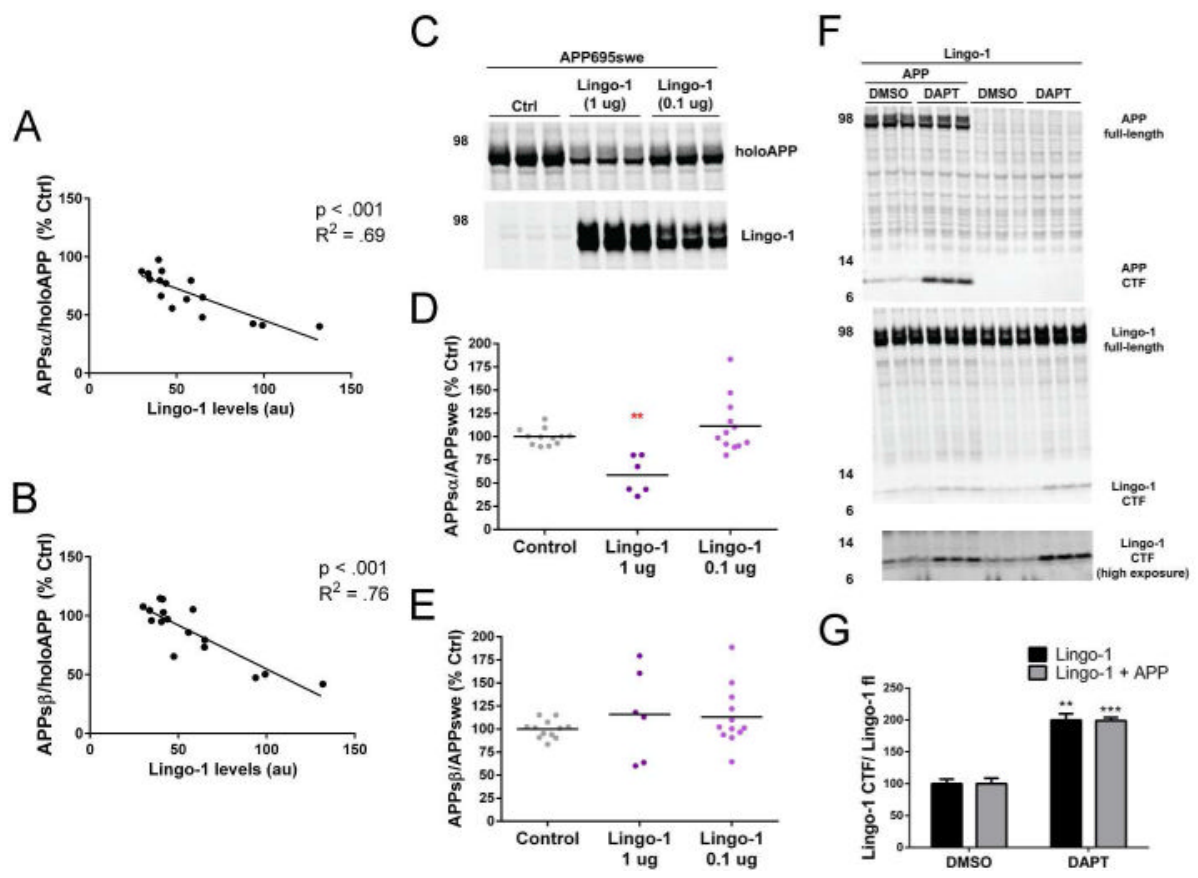

Figure 5. Biochemical analysis of the interaction of Lingo-1 with APP

(A-B) For co-transfection of Lingo-1 and APP751 (human, wild-type) into HEK293 cells, the percent change in APPsa/holoAPP (A) or APPs $\beta /$ holoAPP (B) was graphed as a function of Lingo-1 expression. A regression correlation was performed, and p values represent statistical significance of the slope deviating from 0. (C-E) HEK293 cells were transfected with APP695-swedish (human) and either vector only (control) or Lingo-1 (with both $1.0 \mu \mathrm{g}$ and $0.1 \mu \mathrm{g}$ of DNA). (C) Western blot of lysates showing expression levels of holoAPP and Lingo-1. Quantification of APPsa (D) APPs $\beta$ (E) for each replicate of each experiment shown with scatterplots. (F-G) HEK293were transfected with Lingo-1 or Lingo-1 plus APP751 (human, wild-type) and treated for $24 \mathrm{hrs}$ with DAPT or DMSO (as control). (F) Western blot of lysates showing expression levels of holoAPP, APP CTF, Lingo-1 (apparent full-length and CTF). (G) Quantification of Lingo-1 CTF/full-length Lingo-1 with and without expression of APP. **p<.01, ***p<.001 
A

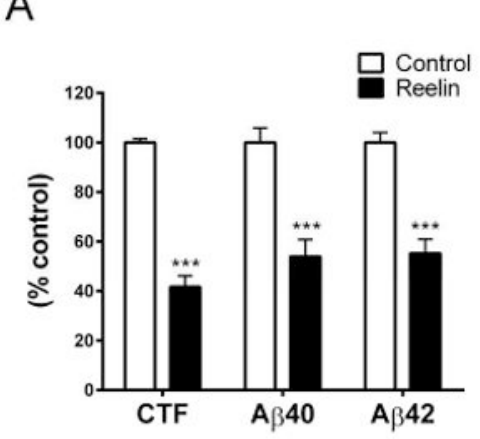

B
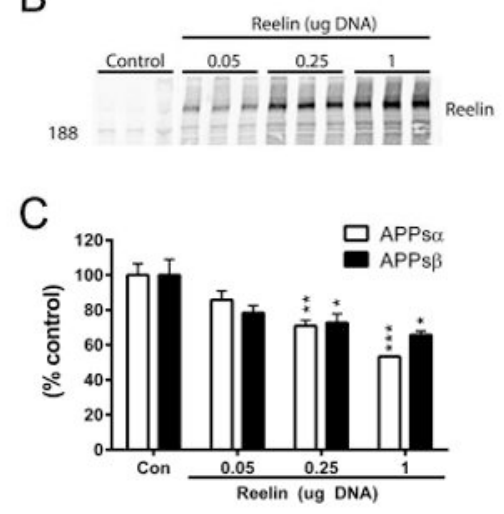

D

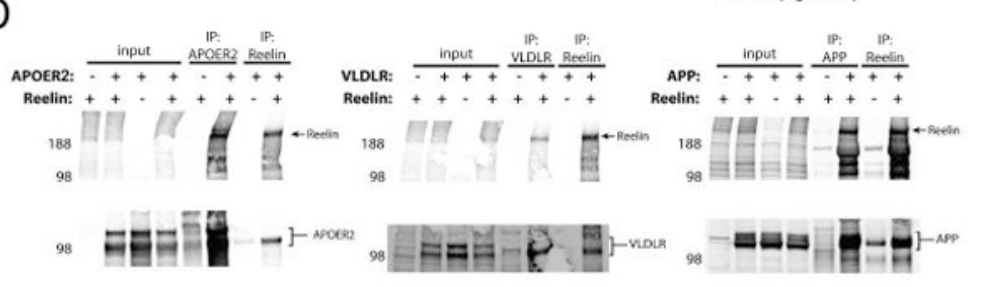

Figure 6. Biochemical analysis of the interaction of Reelin with APP

(A) Quantification of A $\beta 40$, and A $\beta 42$ (by ELISA) and CTF (by WB) in HEK293 assay with over-expression of APP751 (human, wild-type). (B) Reelin expression in CM of HEK293 cells co-transfected with APP751 (human, wild-type) and increased concentrations of Reelin cDNA. (C) Quantification of APPsa and APPs $\beta$ levels in response to increasing Reelin expression. (D) HEK293 cells were transfected with listed combinations of Reelin, APP, APOER2, and VLDLR, and co-IPs were performed for Reelin or else APP, APOER2, or VLDLR. Error bars represent s.e.m.; ${ }^{*} \mathrm{p}<.05,{ }^{* *} \mathrm{p}<.01, * * * \mathrm{p}<.001$ 
A

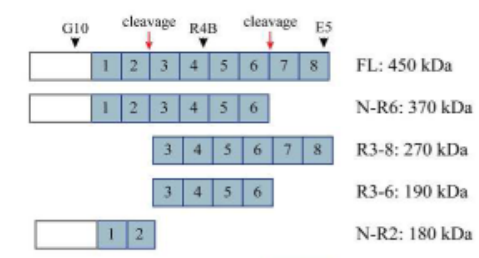

B

\begin{tabular}{|l|l|l|l|l}
\hline 7 & 8 & $\mathrm{R} 7-8: 80 \mathrm{kDa}$ \\
\hline
\end{tabular}

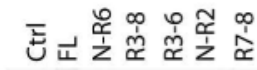

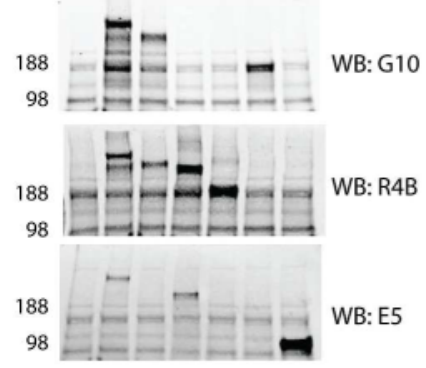

C

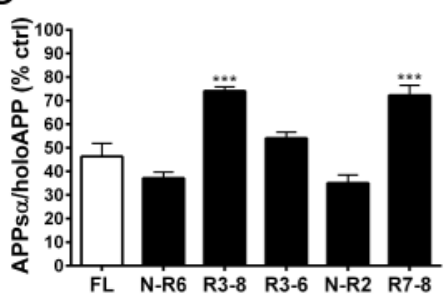

Figure 7. Effects of Reelin fragments on APPsa in HEK293 cells

Schematic of Reelin fragments generated from proteolytic processing. Reelin repeat domains are numbered in blue. Red arrows represent cleavage sites. Black arrowheads represent antibody epitopes. (B) Western blots of cell lysates showing expression of Reelin fragments transfected into HEK293 cells. (C) ELISA quantification of APPsa levels in HEK293 cells co-transfected with APP751 (human, wild-type) and either full-length Reelin or individual Reelin fragments. Error bars represent s.e.m.; ***p<.001, relative to full-length Reelin (FL) 


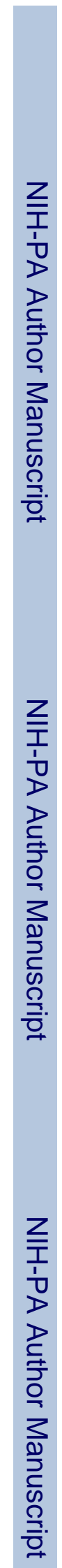

Rice et al.

Page 24

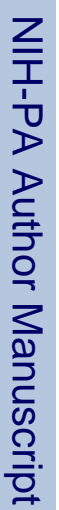

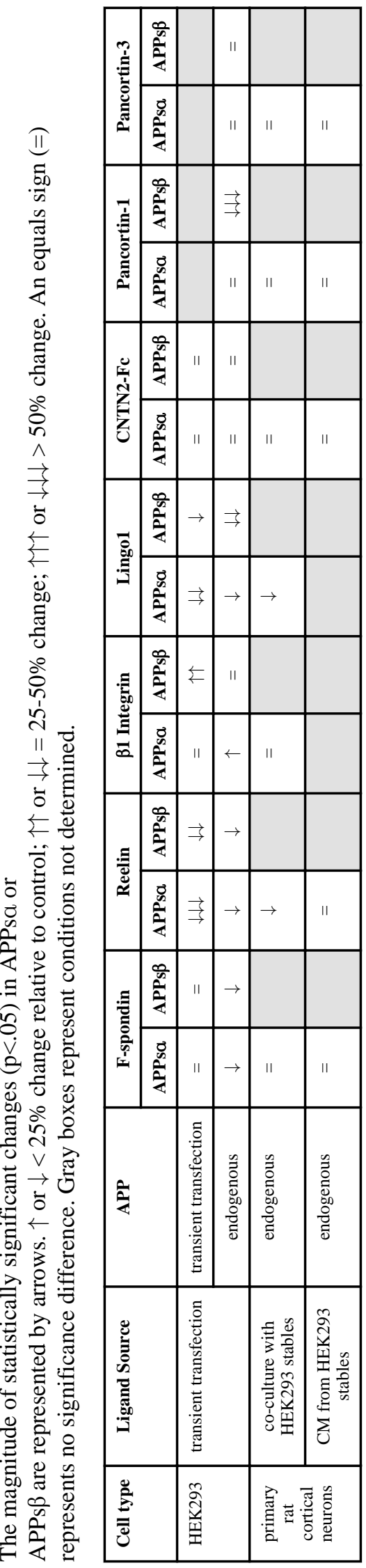

Biochemistry. Author manuscript; available in PMC 2014 May 14. 